\title{
Festas e desenvolvimento local em Cachoeira, Bahia
}

\author{
Celebrations and local development in Cachoeira, Bahia
}

Fiestas y desarrollo local en Cachoeira, Bahia

\author{
Sérgio Ricardo Oliveira Martins ${ }^{1}$ \\ Waleska Rodrigues de Matos Oliveira Martins ${ }^{1}$ \\ Recebido em 10/05/2020; revisado e aprovado em 30/07/2020; aceito em 13/08/2020 \\ DOI: http://dx.doi.org/10.20435/inter.v21i4.3037
}

\begin{abstract}
Resumo: Cachoeira, cidade histórica e culturalmente entre as mais expressivas do Recôncavo da Bahia, é também conhecida pelas inúmeras festas que realiza anualmente. A cidade faz festas para promover o turismo cultural, realizar suas potencialidades e dinamizar sua economia. É precisamente o desenvolvimento local de Cachoeira, que se promove também com as festas, que este artigo objetiva analisar. Este estudo adota uma abordagem processual da história e da realidade social e econômica de Cachoeira, além da observação participante no seu cotidiano e, sobretudo, nas festas juninas, nos últimos quatro anos (2016-2019). Verificouse que Cachoeira experimenta um novo dinamismo econômico, com significativos avanços sociais, com menor dependência de recursos externos e uma crescente capacidade municipal de promover investimentos com base em recursos próprios. Conclui-se, assim, que o turismo cultural, com base na promoção de eventos festivos, tem sido uma das bases mais importantes do desenvolvimento local em Cachoeira.
\end{abstract}

Palavras-chave: festa; turismo; cultura; desenvolvimento local; Recôncavo da Bahia.

Abstract: Cachoeira, a historic town among the most culturally expressive cities of the Recôncavo da Bahia, it is also known for the many celebrations it holds every year. This city makes celebrations to promote the cultural tourism, realize its potentialities and stimulate its economy. The aim of this paper is to analyze the local development of Cachoeira, which is also promoted with the celebrations. This study adopts a procedural approach to the history and the social and economic reality of Cachoeira, in addition to participant observation in its daily life and, above all, June celebrations in the last four years (2016-2019). It was verified that Cachoeira is experiencing a new economic dynamism, with significant social advances, with less dependence on external resources and a growing local capacity to promote investments based on own resources. It is concluded that cultural tourism, based on the promotion of festive events, has been one of the most important bases of local development in Cachoeira.

Keywords: celebration; tourism; culture; local development; Recôncavo da Bahia.

Resumen: Cachoeira, ciudad histórica que es una de las más culturalmente activas en Recôncavo da Bahia, también es conocida por las numerosas fiestas que celebra anualmente. La ciudad hace fiestas para promover el turismo cultural, realizar su potencial e impulsar su economía. El objetivo de este trabajo es analizar el desarrollo local de Cachoeira, que también se promueve con las fiestas. Este estudio cualitativo-cuantitativo adopta un enfoque procesual de la historia y de la realidad económica y social de Cachoeira, además de la observación participante en su vida cotidiana y, sobretodo, en las fiestas juninas en los últimos cuatro años (2016-2019). Se ha comprobado que Cachoeira está experimentando un nuevo dinamismo económico, con importantes progresos sociales, con menor dependencia de los recursos externos y creciente capacidad local para promover inversiones basadas en recursos propios. Se concluye, así, que el turismo cultural, basado en la promoción de eventos festivos, ha sido una de las bases más importantes del desarrollo local en Cachoeira. Palabras claves: fiesta; turismo; cultura; desarrollo local; Recôncavo da Bahia.

\section{INTRODUÇÃO}

No vale do Paraguaçu, Cachoeira se alonga entre a margem esquerda do histórico rio e o relevo colinoso, compondo uma paisagem singular. A cidade de São Félix, situada na margem oposta, liga-se a Cachoeira pela secular ponte Dom Pedro II. O rio, no passado uma importante via de circulação mercantil, teve, na década de 1980, seu regime hídrico alterado pela barragem

\footnotetext{
${ }^{1}$ Universidade Federal do Recôncavo da Bahia (UFRB), Santo Amaro, Bahia, Brasil.
} 
da usina Pedra do Cavalo, situada a montante de onde, outrora, se ancoravam as embarcações na antiga Vila de Nossa Senhora do Rosário do Porto da Cachoeira (Foto 1; Mapa 1).

Foto 1 - Vale do rio Paraguaçu e Cachoeira, BA

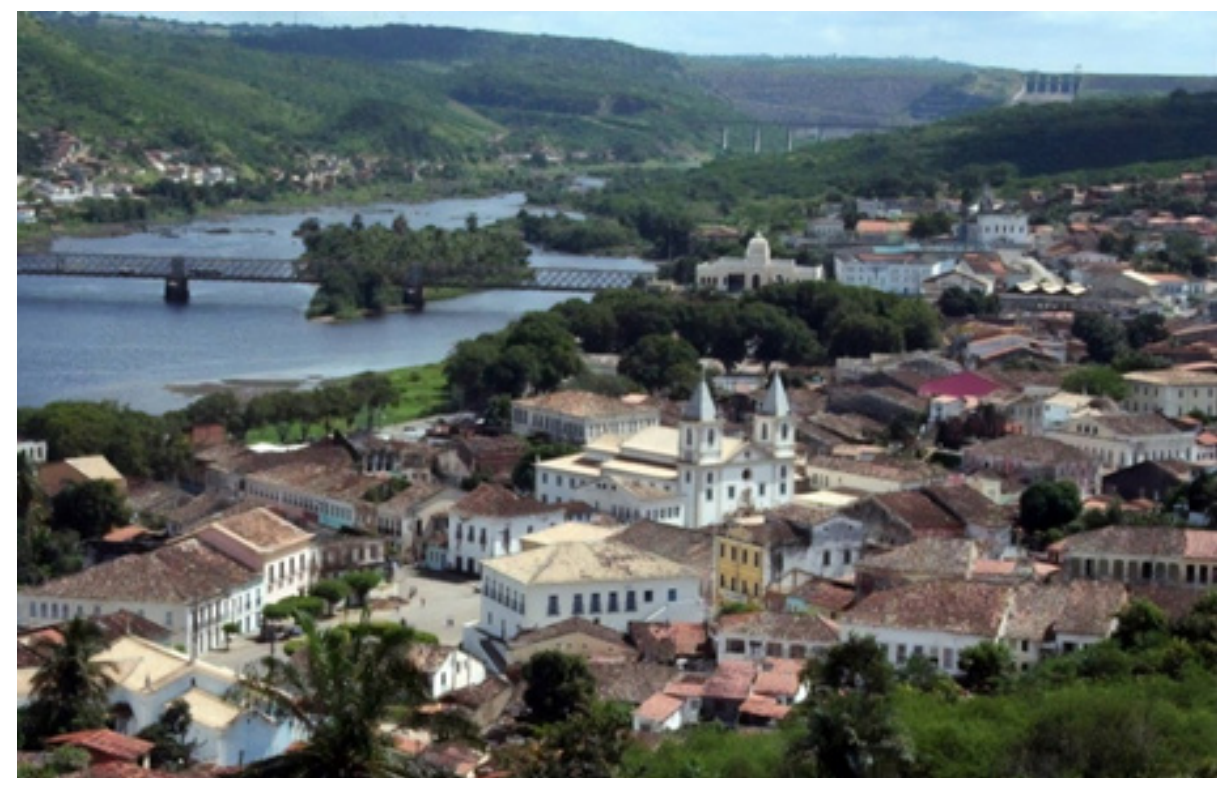

Fonte: Jomar Lima, 2006.

Cachoeira encanta quem quer que caminhe por suas ruas estreitas e contemple o tempo cristalizado na arquitetura e na conformação dos casarios e igrejas, bem como vislumbre sua orla ribeirinha. Não obstante uma população de quase 34 mil habitantes, 51\% dos quais com domicílio urbano ${ }^{2}$, Cachoeira ainda provoca a sensação de que todos se conhecem. O trânsito de pessoas e veículos pelo pequeno centro comercial e os frequentes anúncios dos eventos festivos, religiosos em sua maior parte, produzem movimentos, ritmos e sons que contrastam com a memória da estagnação econômica em que se encontrava Cachoeira até o fim do século XX (FERNANDES; OLIVEIRA, 2012).

O tombamento da cidade, pelo Decreto 68.045, de 13/01/1971, certamente assegurou a base do processo de interiorização do turismo promovido pelo governo estadual, ainda na década de 1970. Como principal atrativo, um patrimônio arquitetônico ímpar, datado dos séculos XVIII e XIX, rugosidades que testemunham sua história e que tornaram Cachoeira elegível pelo Programa Monumenta, com investimentos em obras de recuperação e restauração do patrimônio histórico-cultural, no início dos anos 2000, que formariam a base para que a cidade alcançasse o dinamismo sociocultural e econômico contemporâneo.

\footnotetext{
${ }^{2}$ A estimativa populacional do IBGE para Cachoeira, em 2019, foi de 33.470 habitantes (IBGE, Cidades, 2019).
} 
Mapa 1 - Situação espacial de Cachoeira, BA

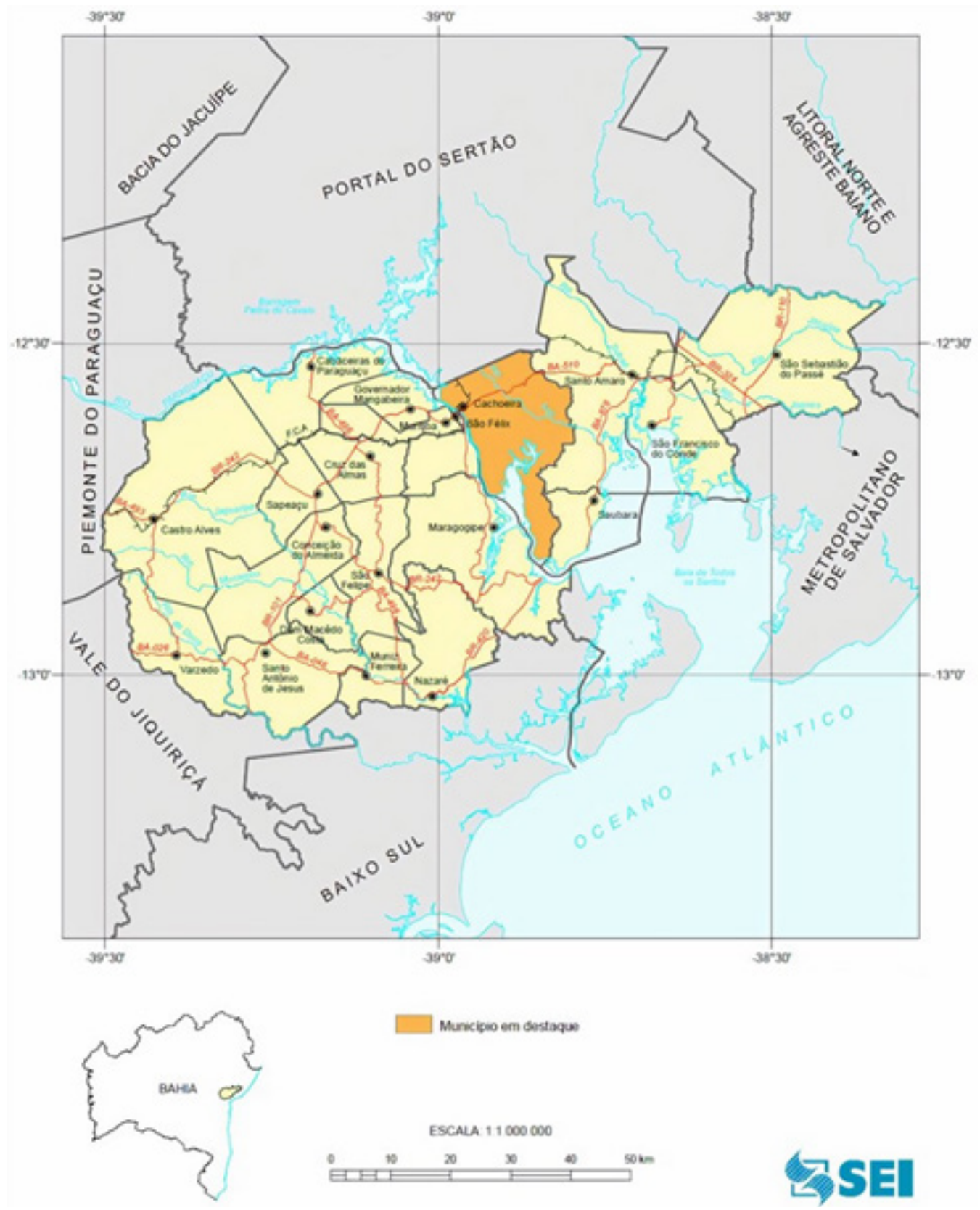

Fonte: Superintendência de Estudos Econômicos e Sociais da Bahia (SEI).

O calendário de eventos festivos de Cachoeira não deixa dúvida: festas ritmizam a cidade, oxigenam sua economia e irrompem a intimidade acústica das moradias. Na conta da Secretaria Municipal de Cultura e Turismo, são 42 festas no calendário anual de Cachoeira. O número é certamente expressivo, mas sobretudo um indicativo de que Cachoeira não apenas faz festas, como também é feita por elas. A festa subverte a mesmice e provoca a estranheza reflexiva entre os "de dentro" e os "de fora". Mas festa também é oportunidade de faturamento comercial, ocupação e renda para muitas cachoeiranas e cachoeiranos. A cidade que faz festas como forma de dinamização econômica e cultural, para além das motivações religiosas e das ambivalências da espetacularização, é o contexto deste estudo, que objetiva analisar esse processo de desenvolvimento que se faz com festas ou que as festas fazem fazer em Cachoeira. 
Este estudo adota uma abordagem processual da história e da realidade social e econômica de Cachoeira. Referencia-se em pesquisas recentes sobre a cidade de Cachoeira sua formação econômica, potencial turístico e especificidades socioculturais. O procedimento adotado busca uma análise mais voltada aos processos, procurando correlacionar dados primários de fontes oficiais com dados secundários produzidos por outros estudos sobre turismo, cultura, festas e desenvolvimento local. A respeito deste último, optou-se pelo aporte teórico-epistemológico do desenvolvimento local enquanto desenvolvimento endógeno e participativo. Conta-se ainda com a observação participante das festas de Cachoeira nos últimos quatro anos (2016-2019), sobretudo em duas das principais festas de Cachoeira em termos de público e movimentação econômica, de acordo com a Secretaria Municipal de Cultura e Turismo: o Esperando São João e o São João Feira do Porto³.

\section{CACHOEIRA ONTEM E HOJE}

A história de Cachoeira tem início nos primeiros anos do século XVI, com as primeiras navegações que se interiorizaram pelo rio Paraguaçu desde a Baía de Todos os Santos. A pequena vila - fundada pouco antes da vertente íngreme e encachoeirada que impunha o ponto final da navegação - se tornaria o epicentro de uma história de mais de 300 anos de exploração econômica do Recôncavo. Cachoeira (e também São Félix, do outro lado do rio) representava os interesses econômicos coloniais centrados em Salvador, como entreposto comercial na ligação com os "sertões" e como centro articulador de uma vasta área produtora de açúcar e fumo, conforme assinalam Fernandes e Oliveira (2012).

Cachoeira experimenta a ascensão e a força econômica da produção açucareira e fumageira, num longo período que vai de meados do séc. XVI ao XIX. O protagonismo na luta pela independência do país alçava sua importância política e econômica e lhe rendia a insígnia de "cidade heroica"4 . Ali, por meados do séc. XIX, Cachoeira era acionada por um amplo tráfego da navegação a vapor que fazia fluir pessoas e mercadorias. A implantação do transporte ferroviário reforçaria ainda mais o dinamismo cachoeirano, de acordo com Fernandes e Oliveira (2012). Alguns anos mais tarde viria o declínio econômico, seja pelo custo e rigidez da estrutura produtiva colonial dos engenhos diante da concorrência internacional, seja pela base escravagista tornada insustentável com a extinção do trabalho de negros escravizados no fim do século XIX (FERNANDES; OLIVEIRA, 2012). Mesmo com a industrialização do fumo pela instalação de fábricas de charuto na região no início do séc. XX, a decadência do modelo agroexportador levava Cachoeira à estagnação econômica, situação que seria reforçada pelo deslocamento imposto pela redefinição do eixo comercial e rodoviário entre Salvador e Feira de Santana nos anos 1940 (SANTOS, 2009).

Entre as décadas de 1940 e 1960, Cachoeira não lembra a dinamicidade que tinha como um dos centros mais importantes da região. Tampouco lembra a situação que fez a cidade merecer a atenção da coroa portuguesa com a concessão da ponte D. Pedro II (ROCHA, 2015).

\footnotetext{
3 Este trabalho faz parte do projeto de pesquisa "Cidades e festas: as ambivalências do Recôncavo da Bahia", financiado pelo CNPq, desde 2019.

4 Pelo protagonismo nas lutas pela independência do Brasil, Cachoeira recebeu a designação de "heroica cidade", de acordo com a Lei n. 43, de 13/03/1837, assinada pelo então presidente da Província da Bahia. O feito histórico é comemorado em 25 de junho, dia em que Cachoeira se torna capital do estado.
} 
Com o comércio e mercado de trabalho retraídos, têm-se os fluxos emigratórios para Salvador, Feira de Santana e para os centros acionados pela exploração e industrialização do petróleo (BRITO, 2008). A produção petrolífera na Baía de Todos os Santos redefiniu o papel do Recôncavo em sua articulação econômica com a capital, no início da década de 1970. À margem desse novo cenário, Cachoeira se aprofundava em um estado economicamente recessivo, enquanto ressentia as transformações e articulações relacionadas às demandas produtivas e logísticas, de base urbana-industrial, a partir de Salvador, cujos fluxos econômicos valorizavam outros centros urbanos da região (SANTOS, 2009).

Em meio à estagnação econômica, havia apenas o patrimônio histórico-cultural e as tradicionais festas de Cachoeira para rememorar os longos anos de glória e efervescência. Essa história deixou testemunhos materiais e imateriais em todo o Recôncavo da Bahia (BA). De forma especial, em Cachoeira, legou um acervo arquitetônico de casarios, sobrados e igrejas em mais de 600 edificações que perfazem o perímetro tombado pelo Instituto do Patrimônio Histórico e Artístico Nacional (Iphan). Como Monumento Nacional ${ }^{5}$, passava a contar com a proteção legal desse patrimônio. Mas, como se sabe, o tombamento não garante a preservação, se dissociado de uma política de planejamento e investimentos que promova sua valorização cultural pela comunidade (RODRIGUES, 2010).

Por outro lado, de acordo com Castro (2009), no Recôncavo, Cachoeira foi pioneira na espetacularização de festas como forma de atrair turistas, movimentar a economia local e firmar sua imagem como cidade histórica e de tradição festiva. Ainda no início dos anos 1970, a Bahiatursa ${ }^{6}$ incumbia-se da realização da festa junina de Cachoeira, fomentando a turistificação do evento (CASTRO, 2009). A proposta tinha, todavia, claros limites na dinamização econômica local, dada a sua efêmera temporalidade, além de não ter força para os necessários investimentos em infraestrutura e qualificação de mão de obra para o turismo. Ainda que oscilando entre períodos de esmorecimento e de agitação econômica, a realização de eventos festivos era certamente uma opção de desenvolvimento a ser considerada, sobretudo, pelo aporte técnico e financeiro do governo estadual (Bahiatursa) em sua política de fomento ao turismo, a partir (também) da promoção de eventos no interior do estado (CASTRO 2009).

É importante assinalar que o estabelecimento de uma política voltada à recuperação econômica de uma pequena cidade, em uma região com deficiências de infraestruturas e alijada do processo de industrialização dos anos 1950 e 1980, como foi o caso do que Santos (2009, p. 77) chama de "velho Recôncavo", precisa ser visto como um processo complexo. Não por outra razão, até o início do séc. XXI, Cachoeira ainda buscava dinamizar a economia local com ações limitadas pela escassez de recursos financeiros (CASTRO, 2009). Até mesmo o turismo cultural, contando com recursos públicos estaduais, ao fomentar a espetacularização de uma festa popular representativa da tradicionalidade cachoeirana, como a festa de São João, era uma opção permeada por ambivalências e manifestações tácitas de contrariedade (CASTRO, 2009).

Nesse contexto, a implantação da Universidade Federal do Recôncavo da Bahia teria desdobramentos significativos em Cachoeira. Criada em 2005, com um significativo aporte de professores(as) e alunos(as), a UFRB trouxe uma nova movimentação para Cachoeira (SILVA; SILVA, 2019). Salários, bolsas de estudo e outras formas de auxílio a estudantes não só aqueceram o

\footnotetext{
${ }^{5}$ Convertida pelo Decreto n. 68.045, de 13 de janeiro de 1971.

${ }^{6}$ Bahiatursa era uma empresa de economia mista que, em 2015, foi incorporada à Secretaria de Turismo da Bahia, tornando-se a Superintendência de Fomento ao Turismo do Estado da Bahia.
} 
mercado imobiliário como também provocaram a ampliação e diversificação do consumo de bens e serviços (FARIAS, 2018).

\section{O NOVO DINAMISMO SOCIAL E ECONÔMICO DE CACHOEIRA}

Obter dados abrangentes que permitam dimensionar, especificamente, os efeitos econômicos e socioculturais do turismo cultural em Cachoeira é uma tarefa, no mínimo, desafiadora, sobretudo, pela pouca sistematização e disponibilidade de dados no nível municipal. Avaliaremos a seguir a produção e arrecadação municipais, os Índices de Performance Econômica (IPE) e de Performance Social (IPS) e o Índice de Desenvolvimento Humano Municipal (IDHM).

A Tabela 1 mostra um aumento do produto interno bruto de Cachoeira da ordem de $750 \%$, de 2000 a 2016. Em valores totais ou setoriais, o Gráfico 1 mostra uma inflexão positiva em todas as curvas a partir de 2012, sendo mais significativa na produção industrial e nos serviços. Em Cachoeira, a participação cada vez mais importante da atividade industrial no PIB tem a ver com o peso relativo de uma grande indústria de beneficiamento de couro em um cenário de poucas unidades fabris de produtos diversos, como charuto, laticínios e licores (SANTOS, 2010). De fato, a implantação da Mastrotto Reichert S/A, em 2000, foi considerada como marco de um novo ciclo de crescimento econômico de Cachoeira. Essa empresa, cuja produção se destina ao mercado internacional, não apenas tem peso no PIB como também na empregabilidade local (SANTOS, 2010).

Tabela 1 - Cachoeira, BA, PIB total e setorial, de 2000 a $2016(R \$ \times 1.000)$

\begin{tabular}{c|c|c|c|c}
\hline \multirow{2}{*}{ Ano } & \multicolumn{4}{|c}{ Produto interno bruto municipal } \\
\cline { 2 - 5 } & Total & Agropecuária & Indústria & Serviços \\
\hline 2000 & 61.492 & 13.186 & 6.952 & 34.054 \\
2002 & 96.798 & 13.183 & 25.916 & 50.089 \\
2004 & 122.449 & 13.174 & 36.360 & 60.350 \\
2006 & 156.016 & 11.817 & 52.612 & 80.162 \\
2008 & 181.165 & 14.234 & 50.843 & 103.076 \\
2010 & 218.593 & 15.683 & 62.273 & 124.600 \\
2012 & 265.347 & 15.294 & 72.025 & 152.769 \\
2014 & 429.673 & 30.854 & 142.620 & 227.436 \\
2016 & 526.800 & 39.518 & 183.812 & 270.115 \\
\hline
\end{tabular}

Fonte: IBGE, 2020.

$$
\begin{aligned}
& \text { Grafico } 1 \text { - Cachoeira, BA - Produto interno } \\
& \text { bruto (PIB) total e setorial, excluindo } \\
& \text { arrecadação (R\$ x 1.000) }
\end{aligned}
$$

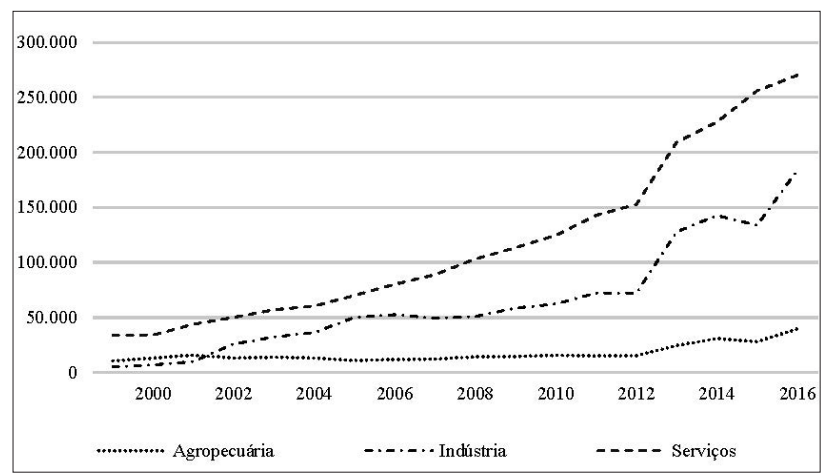

Fonte: IBGE , 2020.

Observa-se que o setor de serviços responde pela maior participação no PIB municipal, incluindo o comércio, atividades imobiliárias, educação, artes, cultura, entre outras atividades (IBGE, 2015; 2020). Ainda que seja difícil dimensionar com números e haja dificuldades técnicas e administrativas a serem superadas, verifica-se a importância do turismo cultural em sua capacidade dinamizadora do comércio e serviços de Cachoeira (QUEIROZ, 2019). De fato, o patrimônio histórico-artístico-cultural tem sido a base de sua potencialidade turística, porém em um contexto ainda carente de planejamento e sensibilização local, como também afirma Castro (2005a). Seja como for, o turismo, atividade principal da recuperação econômica de Cachoeira 
há pelo menos duas décadas, com base no consumo cultural e festivo, está no pano de fundo do aumento ainda mais significativo da arrecadação municipal (cerca de 1.000\%), indicando uma elevação da capacidade de investimentos do poder público local (Tabela 2, Gráfico 2).

Tabela 2 - Cachoeira, BA, arrecadação de impostos, de 2000 a $2016(R \$$ x 1.000)

\begin{tabular}{c|c}
\hline Ano & Arrecadação de impostos \\
\hline 2000 & 3.300 \\
2002 & 9.184 \\
2004 & 12.565 \\
2006 & 11.425 \\
2008 & 13.012 \\
2010 & 16.037 \\
2012 & 25.258 \\
2014 & 28.763 \\
2016 & 33.355 \\
\hline
\end{tabular}

Fonte: IBGE, 2020.
Gráfico 2 - Cachoeira, BA, Arrecadação de impostos $(\mathrm{R} \$ \times 1.000)$

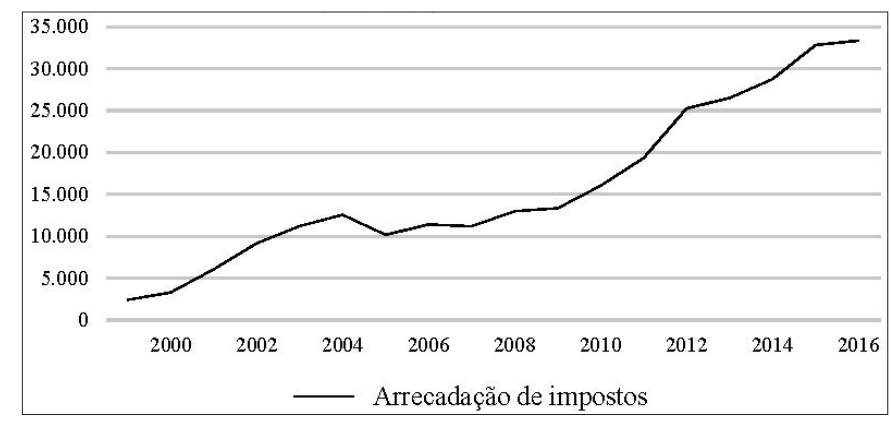

Fonte: IBGE, 2020.

Como desdobramentos desse crescimento econômico e maior disponibilidade de recursos da administração municipal, tem-se uma sensível melhoria das infraestruturas e uma maior independência fiscal de Cachoeira em relação aos recursos externos (maior proporção de recursos próprios em relação aos repasses do estado e da união). Para essa afirmação, consideramos os dois subíndices mais significativos da performance econômica do município, de 2002 a 2010, infraestrutura (INF) e independência fiscal (IIF). De 2002 a 2010, os aumentos dos subíndices INF e IIF situaram Cachoeira na 46a posição em um total de 417 municípios baianos, quanto ao Índice de Performance Econômica (IPE) (Tabela 3). Em sua composição, o IPE avalia a capacidade dos municípios em atender às necessidades de serviços básicos da população, contrapondo a disponibilidade de recursos e seus efeitos sobre a realidade social e econômica (BAHIA, 2014).

Tabela 3 - Índice de Performance Econômica dos Municípios - Cachoeira - 2002 a 2010

\begin{tabular}{c|c|c|c|c|c}
\hline Ano & INF & IPM & ICE & IIF & IPE \\
\hline 2002 & $5.047,30$ & $4.993,52$ & $5.074,81$ & $4.991,46$ & $5.026,65$ \\
2004 & $5.059,02$ & $4.994,87$ & $5.091,34$ & $5.032,31$ & $5.044,26$ \\
2006 & $5.052,79$ & $4.994,37$ & $5.048,82$ & $5.013,93$ & $5.027,42$ \\
2008 & $5.078,46$ & $4.992,86$ & $5.030,21$ & $4.907,66$ & $5.001,90$ \\
2010 & $5.083,13$ & $4.992,59$ & $5.059,84$ & $5.080,72$ & $5.053,94$ \\
\hline
\end{tabular}

INF - Índice de Infraestrutura; IPM - Índice de Produto Municipal; ICE - Índice de Corrente de Comércio Exterior; IIF - Índice de Independência Fiscal; IPE - Índice de Performance Econômica. Valor considerado médio: 5.000.

Fonte: Superintendência de Estudos Econômicos e Sociais da Bahia (BAHIA, 2014).

Vejamos alguns indicadores que podem sinalizar positividades ou melhorias nas condições de vida local. O IDHM de Cachoeira aumentou mais de 60\% desde 1991, com a contribuição significativa de todos os componentes, especialmente, educação (Tabela 4). Ainda que tal progressão tenha por base recursos federais e estaduais investidos em saúde, infraestrutura 
e educação, é importante observar que esses investimentos requerem capacidade local de implementação, em termos de projetos e contrapartidas. Nesse sentido, tal evolução do IDHM se apoiou, também, em permeabilidades políticas e administrativas que permitem entrever ações e recursos locais que, no caso de Cachoeira, são empreendidos há pelo menos duas décadas, no intuito de romper com a falta de dinamismo econômico.

Tabela 4 - Índice de Desenvolvimento Humano Municipal, Cachoeira, BA, 1991, 2000 e 2010

\begin{tabular}{l|l|l|l}
\hline \multicolumn{1}{c|}{ IDHM e componentes } & $\mathbf{1 9 9 1}$ & $\mathbf{2 0 0 0}$ & $\mathbf{2 0 1 0}$ \\
\hline Educação & 0,226 & 0,372 & 0,577 \\
Longevidade & 0,585 & 0,675 & 0,762 \\
Renda & 0,481 & 0,546 & 0,615 \\
Total & 0,399 & 0,516 & 0,647 \\
\hline
\end{tabular}

Fonte: Programa das Nações Unidas para o Desenvolvimento (Pnud). Atlas de Desenvolvimento Humano - Município - Cachoeira, BA.

Os avanços sinalizados pelo IDHM têm a ver com o maior acesso da população, sobretudo dos segmentos mais pobres, aos serviços públicos de educação e saúde, a benefícios sociais e ao mercado de trabalho, ou seja, às condições básicas para ampliar as opções de escolha, essência do conceito de desenvolvimento humano (PNUD, 2020). É o que também mostram o Índice de Performance Social (IPS) e suas variáveis constituintes. O IPS de Cachoeira se manteve próximo a 5.100 (acima desse valor, somente 18 municípios baianos), em virtude da ampliação do nível de educação e dos serviços básicos (Tabela 5). A performance social expressa, precisamente, a utilização de recursos públicos no atendimento às necessidades básicas da população e para reduzir as desigualdades sociais e econômicas (BAHIA, 2014).

Tabela 5 - Índice de Performance Social dos Municípios - Cachoeira - 2002 a 2010

\begin{tabular}{c|c|c|c|c|c}
\hline Ano & ISB & INE & INS & IMT & IPS \\
\hline 2002 & $5.055,43$ & $5.185,61$ & $5.022,79$ & $5.028,63$ & $5.072,69$ \\
2004 & $5.048,12$ & $5.310,93$ & $5.015,55$ & $5.039,95$ & $5.102,33$ \\
2006 & $5.044,05$ & $5.207,43$ & $5.038,38$ & $5.035,91$ & $5.080,93$ \\
2008 & $5.055,43$ & $5.185,61$ & $5.022,79$ & $5.028,63$ & $5.072,69$ \\
2010 & $5.061,84$ & $5.278,34$ & $5.022,36$ & $5.027,92$ & $5.096,54$ \\
\hline
\end{tabular}

ISB - Índice dos Serviços Básicos; INE - Índice do Nível de Educação; INS - Índice do Nível de Saúde; IMT - Índice do Mercado de Trabalho; IPS - Índice de Performance Social. Valor considerado médio: 5.000. Fonte: Superintendência de Estudos Econômicos e Sociais da Bahia (BAHIA, 2014).

Conceitualmente, tanto o IPE quanto o IPS não mensuram desenvolvimento econômico ou social. Suas variáveis expressam a disponibilidade de recursos e sua gestão, nas três esferas do poder público, voltada à promoção de melhorias locais. Certamente há avanços importantes, como a menor concentração de renda (Índice de Gini de 0,64, em 1991, a 0,56, em 2010), mas a população considerada pobre (renda domiciliar per capita inferior a R\$140,00) é ainda significativa (33,8\% do total), como também a de analfabetos (cerca de $20 \%$ da população com 25 ou mais anos de idade), de acordo com o Pnud (Atlas de Desenvolvimento Humano). 
Esse panorama de avanços qualitativos e quantitativos do município de Cachoeira evidencia um novo dinamismo social e econômico, menos dependente de recursos externos e com melhorias em dimensões importantes da qualidade de vida de um lugar, como a cobertura dos serviços de saúde, acesso à educação e à renda. Na base desse processo, estão os investimentos do poder público municipal na promoção dos eventos festivos, como meio de realizar um reconhecido potencial turístico (patrimônio histórico-artístico-cultural). Entre comemorações cívicas, celebrações religiosas e outros eventos, as festas dialogam cultural e politicamente e parecem confluir numa narrativa de sucesso socioeconômico. Levemos nossa atenção a esse panorama festivo, ao sabor metafórico de uma vigorosa "Cachoeira" de festas.

\section{UMA CACHOEIRA DE FESTAS}

Se festa é presentificação de rituais (religiosos ou não) e seus ritmos, de relações estabelecidas nos fazeres festivos, ela instiga e faz pensar a dinâmica das trocas de experiências sociais e identitárias (PEREZ, 2011). A cidade de Cachoeira, nas apropriações e nos usos de seus espaços e nas vivências das simbologias que a humanizam como lugar, (re)inventa suas festas, promove sua imagem e busca maior atratividade turística. Ao empoderar-se de um significativo patrimônio histórico-cultural, a cidade busca se reconhecer no diálogo (tenso!) entre a memória de um passado pujante e um presente de dificuldades estruturais, deficiências técnicas e econômicas que ainda caracterizam a maior parte dos municípios brasileiros do interior, especialmente no Nordeste (IBGE, 2015). A religiosidade sincrética, as reminiscências de uma arquitetura barroca, a musicalidade e a culinária tipicamente baianas, com fortes raízes africanas, consubstanciam imagens ofertadas por Cachoeira, como se pode ver em um folder distribuído pela Secretaria Municipal de Cultura e Turismo de Cachoeira:

A Cidade Heroica e Monumento Nacional tem na sua arquitetura, sua história e tradições o fascínio que encanta visitantes de todo o mundo. [...] Cachoeira preserva o acervo barroco da sua arte sacra e o legado ancestral do povo de santo com seus famosos Terreiros de Candomblé. [...]. Nas festas, a alegria está presente nas ruas, ladeiras e praças históricas. (CACHOEIRA, s.d.).

Ou ainda, como disse o então presidente do Conselho Municipal de Turismo, em 2016: "Cachoeira é uma cidade ímpar, pois, além de ser um polo cultural, tem sabido desenvolver o seu potencial turístico com grandes eventos, como o São João, a Flica e a Festa D'Ajuda"7 . As narrativas dessas descrições reproduzem a imagem-síntese da cidade e ressaltam os elementos que formam a base de seu desenvolvimento contemporâneo: cultura, turismo e festas. Assim, entendemos que a promoção do turismo cultural em Cachoeira com base nas festas tem se firmado como estratégia de geração de trabalho e renda e dinamização sociocultural. Valorizar o lugar, celebrar suas singularidades e sua história, reforçar a conexão entre sagrado e profano, incentivar experiências de interação, mobilizar uma narrativa de sucesso, eis as festas para além de seus efeitos econômicos em todo o Recôncavo, retomando memórias ancestrais, produzindo e/ou reafirmando representações identitárias étnicas e territoriais (TAVARES et al., 2019).

$\mathrm{Na}$ área rural, em 16 comunidades quilombolas registradas do município, são 14 festas realizadas ao longo do ano. Entre elas, destacam-se: Esmola Cantada para São Roque, que percorre os Quilombos do Vale do Iguape (Engenho da Ponte, Engenho da Praia, Kalembá,

\footnotetext{
${ }^{7}$ Entrevista concedida por Daniel Santana, então presidente do Comtur/Cachoeira, em 2016, ao Guia do Turismo Brasil.
} 
Kaonge, Dendê, Engenho Novo e Santiago do Iguape); Festa de São Roque, realizada no Engenho da Ponte; Festa de São Pedro, no Quilombo de Santiago do Iguape; Festa da Ostra, no Quilombo do Kaonge (TAVARES et al., 2019). Na área urbana, acontecem mais 28 eventos festivos, que estão relacionados no quadro 1.

Quadro 1 - Panorama de eventos festivos da cidade de Cachoeira, BA

\begin{tabular}{|c|c|}
\hline MÊS & EVENTO FESTIVO \\
\hline Janeiro & - Terno de Reis Esperança da Paz - Parte do Rosarinho e segue pelas ruas da cidade. \\
\hline Fevereiro & $\begin{array}{l}\text { - Festa de lemanjá - Organizada pelos terreiros de candomblé e prefeitura municipal. } \\
\text { Além da tradicional ritualística das oferendas à lemanjá realizada no porto, ocorrem } \\
\text { as apresentações e shows musicais. É a segunda maior festa de celebração à lemanjá } \\
\text { da Bahia. }\end{array}$ \\
\hline Março & $\begin{array}{l}\text { - Aniversário de Cachoeira - A festa celebra sua elevação à categoria de cidade em } \\
13 / 03 / 1837 \text {. }\end{array}$ \\
\hline Abril & $\begin{array}{l}\text { - Semana Santa - Realizada na Igreja da Matriz e Ordem Terceira do Carmo. } \\
\text { - Recôncavo Jazz Festival - Teve } 3 \text { edições, sendo a 1a realizada em Cachoeira, em } \\
\text { 2012; a 2ạ, em Muritiba, em 2015; e a 3ạ e até o momento última, também em } \\
\text { Cachoeira, em } 2017 . \\
\text { - Reconvexo: Festival de Vídeos e Projeções Mapeadas da América Latina, em vários } \\
\text { espaços da cidade, teve edições de } 2013 \text { a } 2017 \text {. }\end{array}$ \\
\hline Maio & $\begin{array}{l}\text { - Paisagem Sonora: Mostra Internacional de Arte Eletrônica do Recôncavo da Bahia, } \\
\text { teve edições em 2013, } 2015 \text { e } 2017 . \\
\text { - Festa do Divino, na Igreja Matriz de Nossa Senhora do Rosário e cortejo pela cidade. }\end{array}$ \\
\hline Junho & $\begin{array}{l}\text { - Esperando São João, que antecede a Festa de São João Feira do Porto, desde } 2005 . \\
\text { - Corpus Christi, na Igreja Matriz. } \\
\text { - Trezena de Santo Antônio, no Distrito de Capoeiruçu. } \\
\text { - São João Feira do Porto, o maior evento festivo de Cachoeira. } \\
\text { - } 25 \text { de Junho: Independência da Bahia, dia em que Cachoeira se torna capital da } \\
\text { Bahia, em reconhecimento ao seu protagonismo nas lutas pela independência. }\end{array}$ \\
\hline Julho & - Festa de Nossa Senhora do Carmo, realizada na Igreja da Ordem Terceira do Carmo. \\
\hline Agosto & $\begin{array}{l}\text { - Festa da Nossa Senhora da Boa Morte, realizada desde } 1820 \text { pela Irmandade da } \\
\text { Boa Morte, uma confraria criada no séc. XIX, associada à luta contra o regime } \\
\text { escravocrata. }\end{array}$ \\
\hline Setembro & $\begin{array}{l}\text { - Cachoeira Doc: Festival de Documentários de Cachoeira - Programação de debates, } \\
\text { palestras, oficinas e mostras cinematográficas. Teve oito edições de } 2010 \text { a } 2017 . \\
\text { - Festa de Nossa Senhora do Amparo, realizada na Igreja do Monte. } \\
\text { - Festa de Cosme e Damião, na Igreja Nossa Senhora dos Remédios e Igreja São } \\
\text { Cosme e Damião. } \\
\text { - Caruru dos } 7 \text { Poetas: Recital com gostinho de dendê - Constitui-se de manifestações } \\
\text { literárias e religiosas de matriz africana. Teve edições anuais de } 2004 \text { a } 2018 .\end{array}$ \\
\hline Outubro & $\begin{array}{l}\text { - Festa do Orago: Nossa Senhora do Rosário - Padroeira de Cachoeira, na Igreja da } \\
\text { Matriz. } \\
\text { - Festival Origens - Reúne empresários do ramo do tabaco e apreciadores de charutos } \\
\text { de diferentes partes do Brasil, com três edições realizadas: 2017, } 2018 \text { e } 2019 \text {. } \\
\text { - Festa Literária Internacional de Cachoeira (Flica), realizada desde } 2011 .\end{array}$ \\
\hline
\end{tabular}




\begin{tabular}{|c|l|}
\hline MÊS & \multicolumn{1}{c|}{ EVENTO FESTIVO } \\
\hline \multirow{3}{*}{ Novembro } & $\begin{array}{l}\text { - Festa de Nossa Senhora da Ajuda, o "carnaval" de Cachoeira, realizada, pelo menos, } \\
\text { - Fesde } 1872 .\end{array}$ \\
& $\begin{array}{l}\text { Mosta de Santa Cecília - Realizada na Igreja de Nossa Senhora da Conceição do } \\
\text { - Semana Nacional da Consciência Negra - Realizada no Cine Theatro Cachoeirano. }\end{array}$ \\
\hline Dezembro & $\begin{array}{l}\text { - Festa de Santa Bárbara - Realizada na Igreja da Misericórdia. } \\
\text { - Festa de Nossa Senhora da Conceição do Monte - Realizada na igreja de mesmo } \\
\text { nome. }\end{array}$ \\
\hline
\end{tabular}

Fonte: Secretaria Municipal de Cultura e Turismo de Cachoeira, BA, e Tavares et al. (2019).

Na perspectiva do turismo cultural, tem-se um amplo espaço de inter-relações entre distritos, vilas, quilombos e núcleos comunitários. Trata-se de uma orquestração exercida pela prefeitura, via Secretaria Municipal de Cultura e Turismo, a partir da cidade. Como temos observado, nas festas de maior público sediadas no centro da cidade, cada vez mais tem espaço a economia criativa, com a presença da agricultura familiar e de artesanatos de Cachoeira (seus distritos e territórios) e municípios vizinhos.

Nessa profusão de festas, algumas são seculares e patrimonializadas. A Festa de Nossa Senhora da Boa Morte e a Festa da Nossa Senhora D’Ajuda, ambas com mais de 200 anos de história, foram oficialmente registradas no Livro de Registro Especial dos Eventos e Celebrações como patrimônios imateriais da Bahia, pelo Instituto do Patrimônio Artístico e Cultural (Ipac), respectivamente, em 2010 e $2017^{8}$. A Festa da Boa Morte insere Cachoeira em roteiros turísticos internacionais voltados às celebrações religiosas com base no sincretismo entre a fé católica e a religiosidade de matriz africana (CASTRO, 2005b).

As festas religiosas, cerca de $75 \%$ do total, formam um conjunto com grande variação de tempos e usos do espaço urbano, desde as imemoriais Festa da Boa Morte e de Nossa Senhora D'Ajuda às festas de louvor à padroeira Nossa Senhora do Rosário e outros santos católicos (TAVARES et al., 2019). Por outro lado, aproximadamente $1 / 3$ das festas são realizadas em territórios quilombolas, consideradas "ressurgidas" ou "reinventadas" na luta dessas comunidades contra a invisibilização histórica e pela reafirmação de sua origem e etnicidade (TAVARES et al., 2019). É importante considerar que essas festas vêm firmando a perspectiva econômica do turismo étnico, como forma de se visibilizarem, por meio de manifestações artísticas e culturais.

Uma dimensão mais clara da opção cachoeirana pelas festas é apresentada pela Tabela 6 , que registra apenas os novos eventos festivos que se acrescentaram à agenda cultural de Cachoeira, a partir de 2004. Verifica-se que, dos 11 eventos relacionados, cinco estão ativos e os demais foram interrompidos, basicamente, pela insuficiência ou falta de recursos financeiros à sua realização. Entre os ativos, estão os eventos que têm se sustentado apesar da crise financeira a partir de 2014. A situação financeira precária da maioria dos estados e municípios do país tem resultado em fortes limitações nas despesas correntes essenciais e, mais ainda, na capacidade de investimentos e apoios promocionais (IBGE, 2019). No panorama da situação fiscal das unidades da Federação, segundo estudo divulgado em 2018, a Bahia teve classificação "muito fraca", evidenciando maior dificuldade com as contas públicas, mais ainda com sua capacidade

\footnotetext{
${ }^{8}$ Decretos estaduais n. 12.227, de 01/07/2010, e 17.590, de 04/05/2017.
} 
de investimentos ${ }^{9}$. Tem-se a queda no repasse aos municípios, a escassez de editais de apoio e, por conseguinte, a incerteza da continuidade dos eventos dependentes dós recursos estaduais.

Tabela 6 - Novas festas no calendário do município de Cachoeira

\begin{tabular}{c|c|c|c}
\hline Festa & Surgimento & Última edição & Status \\
\hline Caruru dos 7 Poetas & 2004 & 2018 & Interrompida \\
Esperando São João & 2005 & 2019 & Ativa \\
Festa da Ostra & 2009 & 2019 & Ativa \\
Cachoeira Doc & 2010 & 2017 & Interrompida \\
Flica & 2011 & 2019 & Ativa \\
Recôncavo Jazz & 2012 & 2017 & Interrompida \\
Reconvexo & 2013 & 2017 & Interrompida \\
Paisagem Sonora & 2013 & 2013 & Interrompida \\
Festival Origens & 2017 & 2019 & Ativa \\
Festival Gastronômico Samba e Sabores & 2016 & 2016 & Interrompida \\
Festival do Licor de Cachoeira & 2018 & 2019 & Ativa \\
\hline
\end{tabular}

Fonte: Secretaria Municipal de Cultura e Turismo de Cachoeira, BA; Tavares et al. (2019); observação participante.

Não obstante as interrupções (eventos suspensos ou cancelados) no calendário festivo de Cachoeira, o discurso oficial traz uma constante narrativa de sucesso em torno de alguns projetos festivos bem-sucedidos e seus efeitos financeiros. É o que se observa na realização do Festival Origens, que acontece em Cachoeira desde 2017 e revela um discurso não apenas cultural, mas sobretudo econômico, na promoção de um setor emblemático na história regional, a produção do fumo. Entendemos que essa narrativa de sucesso se sustenta, principalmente, na promoção de eventos festivos consolidados e de grande alcance e atratividade de público, como a Festa da Boa Morte e o São João Feira do Porto, entre os mais antigos, e o Esperando São João e a Festa Literária Internacional de Cachoeira (Flica), entre os mais recentes.

$\mathrm{Na}$ impossibilidade de considerar os efeitos de todas as festas (dados os limites deste texto), trataremos dos efeitos socioeconômicos do principal evento festivo de Cachoeira, pelo menos, desde 1990, o São João. Na verdade, essa festa tem projeção econômica significativa na maioria dos municípios do interior da Bahia e da região Nordeste, por movimentar recursos financeiros em proporções que impactam substancial e positivamente as contas municipais e o faturamento de restaurantes e vendedores ambulantes de alimentos e bebidas (BAHIA, 2013).

O São João Feira do Porto de Cachoeira ${ }^{10}$ é uma festa cada vez mais espetacularizada que busca concorrer em atratividade com outras localidades da região. Para Castro (2012), alguns elementos observados em Cachoeira evidenciam a espetacularização das festas juninas, como a mercantilização da cultura, a difusão midiática para além do local ou regional e a grande concentração de público em segmentos do espaço urbano. A espetacularização, na atualidade, também se traduz na realização do evento festivo para a construção de uma "imagem-síntese

\footnotetext{
${ }^{9}$ Brasil Econômico. "Só seis estados brasileiros começarão 2019 com boa situação nas contas". Disponível em: https://economia.ig.com.br/2018-12-14/contas-publicas-estados.html. Acesso em: 30 mar. 2020.

${ }^{10}$ Este é o nome o oficial da festa. A feira do porto era um evento de comercialização de produtos que chegavam a Cachoeira pelo rio Paraguaçu no séc. XIX. Atualmente, a feira é constituída por dezenas de barracas de bebidas, comidas e artesanatos, entre outros produtos, ao longo da orla fluvial.
} 
da cidade" (CASTRO, 2012, p. 90) ou na "monumentalidade das formas espaciais efêmeras como um grande palco" (p. 92). No que se refere à "imagem-síntese", as festas (e não apenas o São João) são espaços-tempos bem explorados, pelo poder público local, para afirmação e projeção midiática de Cachoeira como monumento nacional, cidade heroica e que realiza o São João mais "tradicional" da Bahia"1. Não obstante, o que temos verificado, sobretudo nos últimos quatro anos, é um "tradicional" cada vez menos representativo do sentido costumeiro atribuído à festa junina. Em sentido lúdico, do imaginário popular, o "tradicional" São João se caracteriza como festa caipira, familiar ou comunitária, das danças de quadrilha, das ruas e residências decoradas com bandeirinhas coloridas, do forró e, no caso de Cachoeira, dos folguedos, do samba de roda e da feira do porto (ALMEIDA; REIS, 2016; CASTRO, 2009).

Ainda que seja difícil estabelecer, com precisão, marcos temporais nesse processo, segundo Castro (2009), a espetacularização do São João de Cachoeira se inicia no contexto da interiorização do turismo no Estado, a partir de 1980. De acordo com o autor, a "turistificação" com base no "consumo cultural" constituiu a linha de orientação em Cachoeira, no intuito de tornar o São João o evento principal da cidade. E que, também, inicialmente, por ingerência externa (Bahiatursa), esse processo de planejamento e gestão passa a ser conduzido pela municipalidade, mantendo-se o propósito da mercantilização da cultura com base em um turismo cultural de eventos festivos (CASTRO, 2009). Sem dúvida, a Festa de São João tem sido um bom negócio para comerciantes (e ambulantes) e para o poder público municipal.

De acordo com estudo da Superintendência de Estudos Econômicos e Sociais da Bahia (SEI), em 2011, nos nove municípios incluídos na pesquisa, contando com Cachoeira, eram significativos os efeitos econômicos da Festa de São João. A SEI afirma que esses municípios, em um ano, movimentaram juntos cerca de 20 milhões de reais apenas com a realização da festa. Mostra, ainda, que os turistas que visitaram Cachoeira no período junino fizeram isso, majoritariamente (96\%), para participar da festa, tinham idade entre 18 e 40 anos (73\%) e eram procedentes de Salvador (84,7\%). Hospedaram-se, em sua maior parte (80,8\%), em casa de parentes e amigos, 9,3\% alugaram imóvel e apenas 7,9\% demandaram a restrita rede hoteleira cachoeirana. Os turistas juninos de Cachoeira, em média, permaneceram 3,9 pernoites e gastaram cerca de $\mathrm{R} \$$ 340,00 . E não poderiam ter feito muito mais que isso, considerando uma renda média individual mensal, informada por esses turistas, de 2,8 salários mínimos. O estudo mostra ainda que, em 2013, 36,5\% das empresas em Cachoeira tiveram um acréscimo de mais de 50\% em seu faturamento com a festa e que, para mais de $90 \%$ dos empresários cachoeiranos, a festa favorece o faturamento de suas empresas. O peso econômico do São João foi considerado significativo em municípios como Cachoeira, de pequeno porte, com economia pouco diversificada, tendo cultura e turismo como "vetores" ancorados no patrimônio histórico-cultural e com a festa de São João promovida pela prefeitura municipal (BAHIA, 2013).

O Esperando São João, por sua vez, soa como espécie de aclamação às "origens" do que se considera costumeiro da festa junina. O evento, de acordo com a prefeitura municipal, surge em 2005 com o objetivo de preparar a cidade para o "tradicional" São João Feira do Porto. Com programação que privilegia artistas locais e regionais, bandas de forró, quadrilhas, em estruturas

\footnotetext{
${ }^{11}$ Essa referência ao São João de Cachoeira consta no cartaz de divulgação do evento realizado em 2016 (ver: https://confiramais.com.br/sao-joao-de-cachoeira-bahia-programacao/). Embora a referência não conste mais nos cartazes desde então, a imagem ainda aparece em divulgações mais recentes (ver: https://tvconca.com/2020/03/ viva-festa-junina-sao-joao-de-cachoeira-2020-ja-tem-programacao-confira/).
} 
mais simples e maior proximidade do público, entendemos que o evento atende, em alguma medida, à preocupação de manter o caráter pitoresco, "caipira" e familiar do São João.

Com o Esperando São João, o poder público municipal reforça sua atuação no sentido de promover a economia local. Nesse sentido, o Festival do Licor de Cachoeira, realizado em 2018 e 2019, no âmbito do Esperando São João, não só buscou promover uma típica bebida junina como também, e sobretudo, fortalecer um segmento importante da economia local. A fabricação de licores é uma atividade centenária em Cachoeira. Produzido artesanalmente, os licores cachoeiranos já alçaram reconhecimento nacional por sua qualidade e variedade. Mas a sazonalidade da demanda constitui uma dificuldade do segmento (MORAES; FERREIRA; SABA, 2017). Claramente, o propósito desse festival é aumentar a visibilidade do setor e elevar o seu consumo para além da própria festa, no intuito de reduzir a sazonalidade do mercado.

Assim, as festas, além de projetarem Cachoeira em cenários midiáticos ademais do regional, e enquanto propulsoras do turismo cultural, respondem por significativos efeitos sobre a economia, a cultura e a sociedade locais. A seguir, discutiremos esse processo à luz do desenvolvimento local.

\section{DESENVOLVIMENTO LOCAL EM CACHOEIRA: POR QUE NÃO?}

Ao explorar seu patrimônio arquitetônico, artístico e cultural, com a promoção de eventos festivos, Cachoeira experimenta um desenvolvimento (ainda em grande medida, porém) cada vez menos dependente de aportes financeiros externos e cada vez mais com base em um protagonismo local. É certo que a crise econômica e política em que se encontra o país tem levado as municipalidades a pressionarem por mais recursos estaduais e da União, mas também a buscarem alternativas de atendimento às suas necessidades, tanto quanto possível, a partir de suas potencialidades e recursos.

A percepção dos avanços sociais e econômicos em Cachoeira, nas últimas duas décadas, já levou a considerações indicativas desse processo como desenvolvimento local. São trabalhos que correlacionam os efeitos socioeconômicos da implantação do campus da Universidade Federal do Recôncavo da Bahia (SILVA; SILVA, 2019) e da promoção do turismo cultural e étnico (CASTRO, 2005a; HENRIQUE, 2009). Na mesma perspectiva, também é considerado o Monumenta, um programa estratégico que, de acordo com o lpac $^{12}$, busca conciliar recuperação e preservação do patrimônio histórico-cultural com o desenvolvimento socioeconômico em cidades históricas. Sua implementação em Cachoeira, a partir de 2002, resultou em investimentos de R\$ 36,9 milhões em obras de recuperação e restauração de imóveis públicos e privados, como também na qualificação de pessoas e promoção de atividades educativas relacionadas à cultura e ao turismo (FARIAS, 2018). Não obstante a significativa importância socioeconômica desses incentivos para a localidade, entendemos que uma posição mais conclusiva a respeito de um desenvolvimento local em Cachoeira, ao requerer análises mais abrangentes de sua realidade política, social e econômica, à luz de discussões conceituais que contemplem a complexidade e os desafios operacionais da referida modalidade de desenvolvimento, não cabe nos limites deste texto. Todavia consideramos que esse processo de desenvolvimento de Cachoeira apresenta algumas características fundamentais de desenvolvimento local. Vejamos.

O desenvolvimento local (DL) é, necessariamente, endógeno, ou seja, busca a promoção

\footnotetext{
12 Instituto do Patrimônio Artístico e Cultural da Bahia, autarquia vinculada à Secretaria de Cultura do Estado da Bahia. Sobre o Programa Monumenta, consultar: http://www.ipac.ba.gov.br/preservacao/monumenta.
} 
de potencialidades e atendimento a necessidades locais, com base no protagonismo coletivo ou sociocomunitário (BARQUERO, 2001). A endogenia se ancora, praticamente, no fundamento mais importante do DL, a participação popular ativa. Endógeno é o desenvolvimento promovido de dentro para fora, no sentido de que a dinâmica local se torne menos susceptível e dependente das intenções e dos recursos externos. Promovê-lo é elevar a capacidade local de captar e coordenar a aplicação de recursos externos (BARQUERO, 2001). É o que verificamos em Cachoeira, uma localidade atenta às oportunidades de acesso a recursos externos, que tem racionalizado a utilização desses recursos em função da dinamização de sua economia, a partir do fomento ao turismo cultural com a promoção de um denso calendário festivo. E não se trata de realizar mais e mais festas, mas sobretudo de investir na midiatização dos eventos festivos que mais atraem público e projetam sua imagem, sua história e sua cultura.

"Cachoeira Heroica e Monumento Nacional"13 ou "Tesouro Cultural da Bahia e do Brasil" são insígnias discursivas oficiais, proferidas repetidas vezes em todas as festas e eventos públicos. Além do propósito da valorização, interna e externa, do patrimônio histórico-artístico-cultural, firma-se uma narrativa de afirmação identitária voltada, precipuamente, ao público interno. Ser cachoeirano(a), observamos, acaba por ser mais que um designativo de pertença territorial ou de admiração pela singularidade da composição paisagística da cidade, pois contempla uma história ímpar de protagonismo na luta pela independência do país. Trata-se de um "heroísmo" proclamado pelo poder público e exaltado pela população local. Essa pertença ao espaço e tempo cachoeiranos é ressaltada nas relações, nas faixas comemorativas, em discursos oficiais e nas conversas de bar. Esse sentimento de pertença está entre as "energias intangíveis" do lugar (BOURLEGAT, 2000). É, pois, força para uma concepção de desenvolvimento que valoriza o lugar como referência territorial, cultural e sociocomunitária.

A participação ativa reflete interesses e motivações ancorados em compreensões e vivências da realidade. Interesses, insatisfações, conquistas, sejam individuais, sejam coletivos, motivam a participação e estão totalmente sujeitos às limitações impostas pelas múltiplas diferenciações e desigualdades socioeconômicas, de cidadania e de poder (GOHN, 2019). Nesse sentido, o envolvimento social amplo e ativo em instâncias de decisão ainda é uma variante sensível e comprometedora do caráter necessariamente sociocomunitário e participativo do desenvolvimento local (CATTANI; FERRARINI, 2010).

Em Cachoeira, o processo de elaboração do Plano Diretor municipal, de 2003 a 2006, possibilita avaliar a participação popular em processos políticos de decisão. As ações de esclarecimento e convencimento da população sobre a importância de participar da definição de prioridades de atendimento e investimentos locais, como forma de garantir o caráter necessariamente participativo desse processo, não apenas resultaram em reuniões esvaziadas, mas também em reuniões questionadas e conflituosas, como mostram Teixeira e Silva (2012).

Em 2005, tem-se a criação da Secretaria de Cultura e Turismo, com o objetivo de coordenar as políticas municipais de cultura e de promoção da atividade turística. Em 2013, institui-se o Conselho Municipal de Política Cultural de Cachoeira e, em 2016, o Conselho Municipal de Turismo (CACHOEIRA, 2013, 2016). Trata-se da evolução político-administrativa da gestão da cultura e do turismo em Cachoeira. No que se refere às políticas culturais, o Plano Municipal de Cultura estabelece, entre outras diretrizes, a de promover a economia da cultura como fator de desenvolvimento econômico e social. Pelo programa estratégico I, o plano objetiva valorizar

\footnotetext{
${ }^{13}$ Esta é exatamente a frase que estampa o portal da principal entrada da cidade.
} 
a diversidade cultural com o fortalecimento das "grandes festas populares de Cachoeira" (CACHOEIRA, 2015, p. 33). A realização e o fortalecimento de eventos festivos estão também entre as ações norteadoras da promoção do turismo no município (ALMEIDA, 2017). Em Cachoeira, cultura e turismo se fundem em ações que buscam dinamizar a economia local e sensibilizar a comunidade cachoeirana para a importância potencial de ambos na geração de trabalho, renda e lucratividade.

Os referidos conselhos se constituem como espaço de mediações e discussões entre o poder público e as diferentes representações da sociedade civil cachoeirana. Suas composições contemplam os diferentes segmentos sociais e políticos interessados na gestão da cultura e do turismo no município, incluindo os diversos setores diretamente relacionados, além de várias representações do poder público municipal, estadual e federal (CACHOEIRA, 2013; 2016). Ainda que as reuniões sejam abertas e se estimule a presença popular, a participação tende a ser maior nas discussões que afetam os interesses mercantis associados aos eventos festivos.

Uma clara evidência da nova condição política e econômica de Cachoeira de promover a cultura no município foi o lançamento, em março de 2020, do 10 Edital Municipal Setorial de Cultura, com um aporte de R\$ 711 mil do Fundo Municipal de Cultura a título de fomento a projetos necessariamente cachoeiranos. Foram contemplados 30 projetos em áreas como artes visuais; museus e memórias; audiovisual; música; teatro e dança; cultura popular; literatura; programas e ações de educação patrimonial. Em termos de captação de recursos, de acordo com a Secretaria de Cultura e Turismo, tem-se, especificamente, entre outras fontes estaduais e federais, o Programa de Fortalecimento da Produção Associada ao Turismo Cultural (Programa PAT), uma ação estruturante do Programa Nacional de Desenvolvimento do Turismo (Prodetur Bahia), com o objetivo de apoiar e fortalecer a atividade turística e consolidar a Baía de Todos os Santos como destino turístico.

O caráter precipuamente endógeno, articulado às externalidades institucionais em termos de fontes de recursos públicos ou privados, que têm resultado em progressos econômicos e sociais, permite afirmar que há desenvolvimento local em Cachoeira, mesmo com uma participação popular relativizada em vista dos distintos interesses e possibilidades de decisão. E, nessa questão específica de relações de poder, Cachoeira não poderia ser tão diferente.

\section{CONSIDERAÇÕES FINAIS}

Cachoeira deixou a estagnação para trás, experimentando nas últimas duas décadas um "novo" dinamismo social e econômico. Verificamos que esse processo ainda se apoia, em grande medida, em recursos externos, mas cada vez menos, como mostraram os dados. Observamos, assim, uma progressiva independência fiscal do município, evidenciando uma crescente capacidade municipal de promover investimentos com recursos próprios.

As mudanças socioeconômicas em Cachoeira são, objetivamente, positivas sobre a qualidade de vida local, tomando por base dimensões relacionadas ao desenvolvimento humano (saúde, educação e renda). Consideramos, por fim, que o turismo cultural, com base na política estadual de interiorização da atividade e na política nacional de conservação e valorização sustentável do patrimônio histórico-artístico-cultural cachoeirano, tem sido a base da ascensão econômica e social de Cachoeira, contexto em que as festas, "tradicionais" e espetacularizadas, podem ser consideradas propulsoras de desenvolvimento local. 


\section{REFERÊNCIAS}

ALMEIDA, P. M. R. Gestão turística do município de Cachoeira sob a ótica do turismo responsável. 2017. Dissertação (Mestrado em Gestão de Políticas Públicas e Segurança Social) - Universidade Federal do Recôncavo da Bahia, Cruz das Almas, BA, 2017. Disponível em: https://www.ufrb.edu.br/mpgestaoppss/ dissertacoes/category/14-2017?download=126: pamela-moura-da-rocha-almeida. Acesso em: 31 mar. 2020.

ALMEIDA, R. S.; REIS, R. B. Análise da expressividade cultural do São João de Cachoeira-BA com a contribuição da geotecnologia: a percepção dos moradores locais. Revista Iberamericana de Turismo, Penedo, v. 6, n. 1, p. 94-113, jan./jun. 2016.

BAHIA (Estado). Superintendência de Estudos Econômicos e Sociais do Estado da Bahia. Índice de Performance Econômico e Social dos Municípios Baianos 2002-2010. Salvador: SEI, 2014.

BAHIA (Estado). Superintendência de Estudos Econômicos e Sociais do Estado da Bahia. Efeitos da Festa de São João em municípios selecionados. Salvador: SEI, 2013. [Relatório].

BARQUERO, A. V. Desenvolvimento endógeno em tempos de globalização. Porto Alegre: FEE/UFRGS, 2001.

BOURLEGAT, C. A. Ordem local como força interna de desenvolvimento. Interações, Campo Grande, MS, v. 1, n. 1, p. 13-20, set. 2000.

BRASIL. Ministério do Trabalho e Emprego. Relação Anual de Informações Sociais. Brasília-DF: MTE, 2015.

BRITO, C. A. Petrobrás e a gestão do território no Recôncavo Baiano. Salvador: EDUFBA, 2008.

CACHOEIRA (Cidade). Lei n. 1.150, de 6 de janeiro de 2016. Institui a Política Municipal de Turismo Responsável, o Sistema Municipal de Turismo, o Conselho Municipal de Turismo e dá outras providências. Cachoeira: Prefeitura Municipal, 2016.

CACHOEIRA (Cidade). Lei n. 1.140, de 22 de setembro de 2015. Institui o Plano Municipal de Cultura de Cachoeira para o decênio 2015-2025. Cachoeira: Prefeitura Municipal, 2015.

CACHOEIRA (Cidade). Lei n. 1.000, de 13 de dezembro de 2013. Institui o Conselho Municipal de Política Cultural de Cachoeira. Cachoeira: Prefeitura Municipal, 2013.

CACHOEIRA (Cidade). Secretaria Municipal de Cultura e Turismo de Cachoeira, BA. Folder. Cachoeira: Artemapas, [s.d.].

CASTRO, A. C. O patrimônio histórico-cultural e o turismo na Cidade Heroica de Cachoeira-BA: potencialidade x realidade. Interações, Campo Grande, MS, v. 7, n. 11, p. 113-9, set. 2005a.

CASTRO, A. C. A Irmandade da Boa Morte: Memória, intervenção e turistização da festa em Cachoeira (BA). In: ENCONTRO DE ESTUDOS MULTIDISCIPLINARES EM CULTURA, 1., 2005, Salvador. Anais [...]. Salvador: Edufba, 2005b. Disponível em: http://www.cult.ufba.br/enecul2005/ArmandoAlexandreCastro. pdf. Acesso em: 20 mar. 2020.

CASTRO, J. R. B. Espetacularização e mercantilização das festas juninas na atualidade. In: Da casa à praça pública: a espetacularização das festas juninas no espaço urbano. Salvador: Edufba, 2012. p. 85-146. Disponível em: http://books.scielo.org/id/tqvcj/pdf/castro-9788523211721-04.pdf. Acesso em: 10 abr. 2020. 
CASTRO, J. R. B. O papel das manifestações culturais locais/regionais no contexto da turistificação das festas juninas espetacularizadas em Cachoeira-BA. In: ENCONTRO DE ESTUDOS MULTIDISCIPLINARES EM CULTURA, 5., 2009, Salvador. Anais [...]. Salvador: Edufba, 2009. Disponível em: http://www.cult.ufba.br/ enecult2009/19383.pdf. Acesso em: 5 nov. 2019.

CATTANI, A. D.; FERRARINI, A. V. Participação, desenvolvimento local e política pública: estratégias articuladas para a superação da pobreza. Revista Katál, Florianópolis, v. 13, n. 2, p. 164-72, jul./dez. 2010.

FARIAS, S. C. O Programa Monumenta e a sua implementação em Cachoeira. 2018. Dissertação (Mestrado em Teoria e História da Arquitetura) - Faculdade de Arquitetura e Urbanismo, Universidade de Brasília, Brasília, 2018. Disponível em: https://repositorio.unb.br/bitstream/10482/33914/1/2018_ SylvioCarneirodeFarias.pdf. Acesso em: 31 mar. 2020.

FERNANDES, R. B.; OLIVEIRA, L. C. S. Evolução econômica do município de Cachoeira (BA): do século XVI ao século XXI. In: SIMPÓSIO CIDADES MÉDIAS E PEQUENAS DA BAHIA, 3., 2012, Feira de Santana. Anais [...]. Feira de Santana: UEFS, 2012. Disponível em: http://anais.uesb.br/index.php/ascmpa/article/ viewFile/3747/3431. Acesso em: 30 mar. 2020.

GOHN, M. G. Teorias sobre participação social: desafios para a compreensão das desigualdades sociais. Caderno CRH, Salvador, v. 32, n. 85, p. 63-81, jan./abr. 2019.

GUIA DO TURISMO BRASIL. Entrevista concedida por Daniel Santana, então presidente do Comtur/ Cachoeira, em 2016. Disponível em: https://www.guiadoturismobrasil.com/noticia/645/festivalgastronomico-movimenta-cachoeira-ba-ate-sabado. Acesso em: 22 mar. 2020.

HENRIQUE, W. A instalação da UFRB, a ação do Programa Monumenta e o turismo étnico na reestruturação urbana e no cotidiano de Cachoeira-BA: Notas preliminares de pesquisa. Revista GeoTextos, Salvador, v. 5, n. 1, p. 89-112, jul. 2009.

IBGE. Produto Interno Bruto dos Municípios. Rio de Janeiro: IBGE, 2020. (Cidades@) Disponível em: https:// cidades.ibge.gov.br/brasil/ba/cachoeira/pesquisa/38/46996. Acesso em: 15 mar. 2020.

IBGE. Sistema de informações e indicadores culturais 2007-2018. Rio de Janeiro: IBGE, 2019. (Estudos e pesquisas, informação demográfica e socioeconômica, n. 42).

IBGE. Perfil dos estados e dos municípios brasileiros: Cultura 2014. Rio de Janeiro: IBGE, 2015.

MORAES, F.; FERREIRA, D.; SABA, H. Indicação de procedência: potencial do Recôncavo da Bahia no reconhecimento da produção artesanal de licores de frutas. Conjuntura e Planejamento, Salvador, n. 193, p. 63-77, jul./dez. 2017.

PEREZ, L. F. Festa para além da festa. In: PEREZ, L. F.; AMARAL, L.; MESQUITA, W. Festa como perspectiva e em perspectiva. Rio de Janeiro: Garamond, 2011. p. 21-42.

PROGRAMA DAS NAÇÕES UNIDAS PARA O DESENVOLVIMENTO. O que é desenvolvimento humano. [S. I.]: Pnud, 2020. (Atlas de Desenvolvimento Humano). Disponível em: https://www.br.undp.org/content/ brazil/pt/home/idho/conceitos/o-que-e-desenvolvimento-humano.html. Acesso em: 23 mar. 2020.

QUEIROZ, L. M. A. Turismo cultural e desenvolvimento: Cachoeira \& Ouro Preto. Cruz das Almas: EDUFRB, 2019.

ROCHA, R. Cachoeira, Joia do Recôncavo Baiano. Tucano, BA: Gráfica Tibiriçá, 2015. 
RODRIGUES, M. P. J. Caminhos da preservação: políticas, patrimônio material e reflexos nas dinâmicas social e urbana de Cachoeira-BA. 2010. Dissertação (Mestrado em Cultura, Memória e Desenvolvimento Regional) - Universidade do Estado da Bahia (Uneb), Santo Antônio de Jesus, BA, 2010. Disponível em: http://livros01.livrosgratis.com.br/cp145888.pdf. Acesso em: 10 abr. 2020.

SANTOS, A. G. P. A implantação da indústria de beneficiamento de couro Mastrotto Reichert S/A e as implicações socioespaciais no município de Cachoeira-BA. 2010. Dissertação (Mestrado em Geografia) Instituto de Geociências, Universidade Federal da Bahia, Salvador, 2010. Disponível em: https://repositorio. ufba.br/ri/bitstream/ri/17830/1/Andr\%c3\%a9\%20Gustavo\%20Pinheiro\%20dos\%20Santos.pdf. Acesso em: 31 mar. 2020.

SANTOS, R. S. Cultura política e participação no Recôncavo baiano hoje: uma análise sobre Cachoeira e São Felix. 2009. Dissertação (Mestrado em Ciências Sociais) - Faculdade de Filosofia e Ciências Humanas, Salvador, BA, 2009. Disponível em: https://repositorio.ufba.br/ri/bitstream/ri/11359/1/Dissertacao\%20 Rubenilda\%20Santosseg.pdf. Acesso em: 31 mar. 2020.

SILVA, J. A. S.; SILVA, O. R. Políticas públicas de educação superior e desenvolvimento local: as transformações no município de Cachoeira (BA) após a implantação da Universidade Federal do Recôncavo da Bahia. Revista Eletrônica Direito e Sociedade, Santa Cruz do Sul, v. 24, n. 2, p. 209-32, maio/ago. 2019.

TAVARES, F.; CAROSO, C.; BASSI, F.; RAMOS, C. Inventário das festas e eventos na Baía de Todos os Santos. Salvador: Edufba, 2019.

TEIXEIRA, N.; SILVA, M. G. Participação popular: o caso do plano diretor de Cachoeira. In: SIMPÓSIO CIDADES MÉDIAS E PEQUENAS DA BAHIA, 3., 2012, Feira de Santana. Anais [...]. Feira de Santana: Uefs, 2012. Disponível em: http://anais.uesb.br/index.php/ascmpa/article/viewFile/3725/3410. Acesso em: 22 abr. 2020.

\section{Sobre os autores:}

Sérgio Ricardo Oliveira Martins: Doutor e mestre em Geografia Humana pela Universidade de São Paulo (USP). Graduado em Geografia pelas Faculdades Unidas Católicas de Mato Grosso (FUCMT). Líder do Grupo de Pesquisa Tempo Ritual e Espaço Festivo, vinculado ao Laboratório de Estudos Interdisciplinares e Interculturais do Centro de Cultura, Linguagens e Tecnologias Aplicadas. Professor associado da Universidade Federal do Recôncavo da Bahia (UFRB). E-mail: sergioolivemartins@gmail.com, Orcid: http://orcid.org/0000-0003-4838-5176

Waleska Rodrigues de Matos Oliveira Martins: Doutora em Estudos Literários pela Universidade Estadual Paulista (Unesp) - Araraquara e mestre em Estudos de Linguagens pela Universidade Federal de Mato Grosso do Sul (UFMS). Graduada em Letras pela Universidade Católica Dom Bosco (UCDB). Membro do Grupo de Pesquisa Tempo Ritual e Espaço Festivo, vinculado ao Laboratório de Estudos Interdisciplinares e Interculturais, do Centro de Cultura, Linguagens e Tecnologias Aplicadas. Professora adjunta da Universidade Federal do Recôncavo da Bahia (UFRB). E-mail: waleskamartins.wm@gmail.com, Orcid: http://orcid.org/0000-0001-9961-152X 
